\title{
Image-Blogs: Consumer Adoption and Usage (Research-in-Progress)
}

\author{
Eleanor T. Loiacono and Purvi Shah \\ Worcester Polytechnic Institute \\ Worcester, MA USA \\ \{eloiacon, pshah\}@wpi .edu
}

\begin{abstract}
Bloggers are now turning to more creative ways to share their knowledge, thoughts, ideas, and opinions (information) while making it an easier experience for them and their viewers. image-blogging has become a tool for those looking to share information through multimedia with their viewers. This paper is part of a larger project looking into a broader investigation of imageblog usage. Understanding what encourages adoption and use of a image blog by its audience is of interest to companies looking to utilize such technologies to their benefit.
\end{abstract}

Keywords: Image-blog, Technology Acceptance Model, Consumer Behavior.

\section{$1 \quad$ Introduction}

Many have taken to blogging as a means of sharing with others. In a broad perspective, blogs refer to "a website that contains an online personal journal with reflections, comments, and often hyperlinks provided by the writer" (Merriam-Webster.com November 1, 2013). Almost seven million (6.7) people blog on websites, while approximately 12 million do so over other social media, such as Twitter. A large portion (77\%) of Internet users read blogs during their time online (McGrail 2013).

The idea of "blogs" started slowly in the late 1990's, but grew fast (Blood 2000). Blogs are now a regular occurrence on the Web. In today's hectic and data-rich world, however, people can easily get overwhelmed with an abundance of textual-based blogs. Bloggers are now turning to more creative ways to share their knowledge, thoughts, ideas, and opinions (information) while making it an easier experience for them and their audiences. Image-blogs are blogs that focus on images (e.g., pictures, photographs, drawings, paintings) to convey thoughts and meaning. They have become a tool for those looking to share information through multimedia with their viewers (see Figure 1). It allows them to get their ideas and opinions across to others with greater efficiency. There is less to write, thus less to read, but more visual data to help convey information to the observer.

This research will serve as the initial study into a broader investigation of imageblog usage. Understanding what encourages adoption and use of an image blog is of interest to companies looking to utilize such technologies to their benefit. Specifically, this study looks at what makes people willing to adopt and continue to use an image blog. The technology acceptance model (TAM) will serve as the theoretical foundations of this research. 


\section{Planning for the future}

\section{September 20, 2013}

\section{Updated Oct. 9: Starting to test promoting pins}

We wanted to let you know that we are starting our first test with promoting pins today, so you may spot a few in your search results or category feeds on the web or in mobile apps. Here's what they look like:

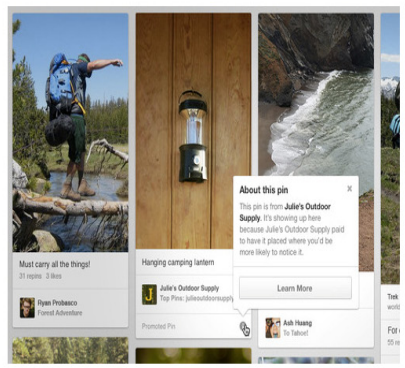

They work just like regular pins, only they have a special "promoted" label, along with a link to learn more about what that means. Remember we're still just testing things out right now, so we'd really like to hear what you think. We'll be listening closely to what you have to say and will continue to keep you posted about how things go.

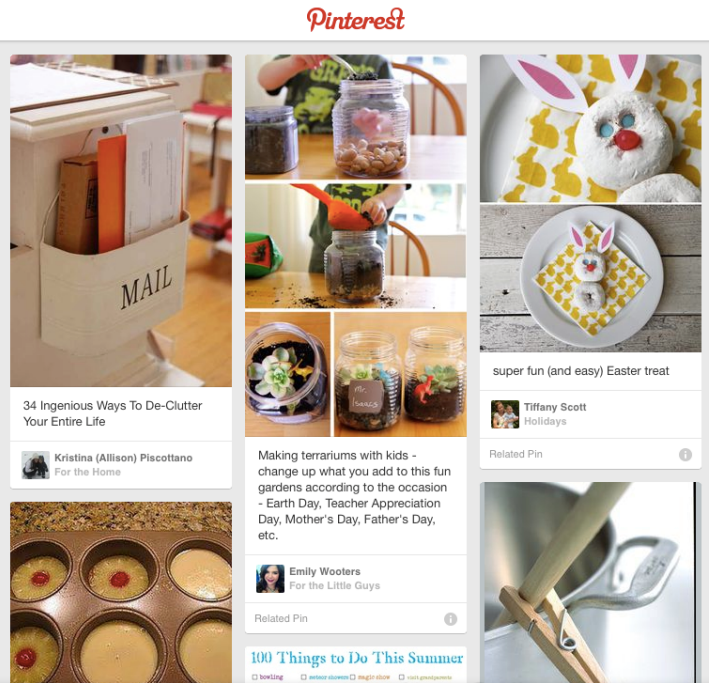

Fig. 1. Samples of Image-blogs

\section{$2 \quad$ Literature Review}

The technology acceptance model (TAM) (Figure 2) consists of two factors: Perceived usefulness and perceived ease of use. Perceived usefulness refers to the "the 
degree to which a person believes that using a particular system would enhance his or her job performance". Perceived ease of use is the "the degree to which a person believes that using a particular system would be free from effort" (Davis, Bagozzi et al. 1989). Both factors impact a person's intention to adopt a particular website.

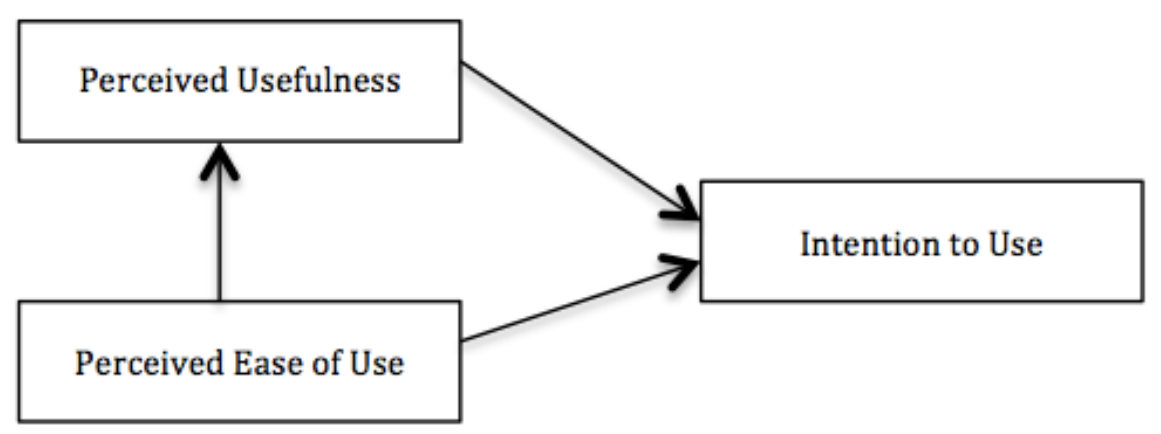

Fig. 2. Technology Acceptance Model

Because image-blogs are online and thus possess similar characteristics to websites, two relevant website quality factors (Loiacono, Watson et al. 2007) are also relevant to this research. They are perceived response time and perceived trust.

TAM and WebQual are well-established frameworks which have been utilized to study the adoption and usage of various information technologies (Venkatesh 2000, Caber, Albayrak et al. 2013). In this research we use a modified TAM, including relevant WebQual factors, to predict adoption and continued usage of an image-blog by users (Figure 3).

At the core of TAM is a person's intention to use a system. If a person does not intend to use a system, then it is of little value. Thus, the factors that impact intention to

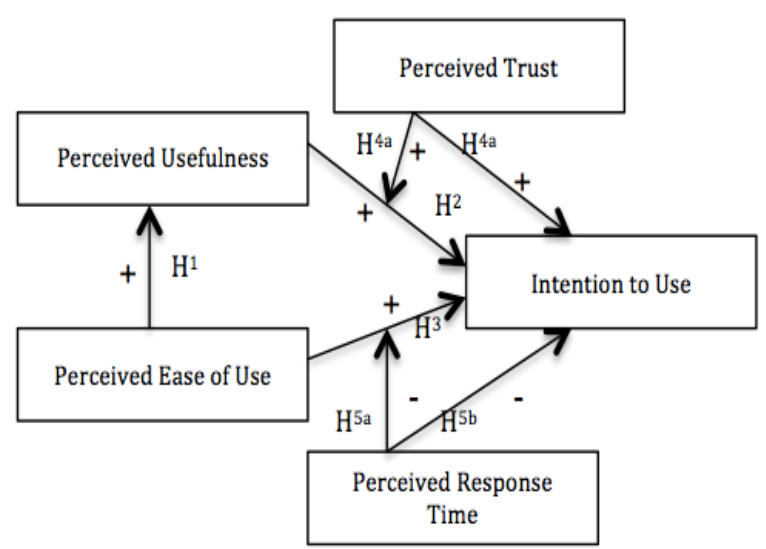

Fig. 3. Research Model 
use are critical to ensure its usage, since there is a high correlation between intention to use and actual usage (Davis, 1989). According to TAM, the two factors that have the greatest impact in a person's intention to use a system are perceived usefulness and and perceived ease of use. Perceived usefulness is defined as "the degree to which a person believes that using a particular system would enhance his or her job performance" (Davis, 1989). Perceived ease of use is "the degree to which a person believes that using a particular system would be free from effort" (Davis, 1989). Additionally, perceived ease of use is has been shown to impact perceived usefulness.

Thus, in terms of image-blog intention to use, it is hypothesized that:

- H1: The perceived ease of use of an image-blog will positively influence perceived usefulness.

- H2: The perceived usefulness of an image-blog will positively influence a person's intention to use it.

- H3: The perceived ease of use of an image-blog will positively influence a person's intention to use it.

Image-blogs are online and viewed using the open Internet. For these reasons the speed and trust in the image-blog are thought to impact the relationship between the two TAM factors and intention to use (Loiacono, Watson et al. 2007). Specifically, the greater the trust in a website, the more likely a person is to use it. Similarly, the faster the response time of the website to a user's request, the more likely a user is to continue use.

Additionally, the trust an individual feels in a website may impact the relationship between perceived usefulness and intention to use. Concurrently, the level of response time may also mediate the relationship between perceived ease of use and intention to use.

Applying this to image-blogs, it is hypothesized that:

- H4a: Trust in the image-blog will positively influence a person's intention to use it.

- H4b: Trust in the image-blog will moderate the relationship between perceived usefulness and intention to use.

- H4a: Response time of the image-blog will negatively influence a person's intention to use it.

- H4b: Response time of the image-blog will moderate the relationship between perceived ease of use and intention to use.

\section{Methodology}

In order to understand the factors that impact image-blog adoption and usage, a survey methodology will be employed. A total of 100 subjects will be solicited to participate. They will be recruited from a northeastern university. They will all be adult online Web users, over the age of 18. Additional demographic information, such as gender, level of education, experience using the Internet, and Web usage will be collected. Prior to beginning the study, subjects will be asked to review and, if they 
agree, sign a consent form, approved by the university's Internal Review Board. The incentive to participate will be a $\$ 3$ gift card to a local coffee shop.

\subsection{Measures}

TAM. The technology acceptance model (Figure 3) consists of two independent factors, perceived usefulness and perceived ease of use, and the dependent factor, behavioral intention to use. The measures will be adapted from previous research (Davis, Bagozzi et al. 1989) where they have shown high internal reliability as well as discriminant and convergent validity.

WebQual. In addition to gathering TAM factors, three questions for both of the adapted WebQual factors, perceived trust and perceived response time, will be collected as well. The measures will be adopted from Loiacono et al. (2007) (See Appendix 1). Each factor has shown high internal reliability and convergent and discriminant validity in past research. Appendix 2 contains the survey items.

Task. Upon accessing the survey site, subjects will be briefed about the study and asked to read and agree to the terms in the consent form before proceeding. Those who are unwilling to participate will be thanked and directed away from the survey site. Those who agree to participate will begin the study by providing some demographic information, such as gender, age, education level, and Web usage. They will then move on to the actual viewing of the image-blog. Next, the subjects will be asked to respond using a 7-point Likert scale as to their agreement with the TAM and WebQual items. Once they finish responding to the survey items, they will be directed to a page thanking them for their participation. The total survey time is not expected to last more than 20 minutes.

\section{$4 \quad$ Expected Results}

Previous research has shown stronger intention to adoption a system based on its perceived usefulness and ease of use. We would expect that the level of perceived trust would positively enhance the impact perceived usefulness has on adoption. Similarly, increased levels of perceived response time would have a negative effect on perceived ease of use.

\section{$5 \quad$ Discussion and Future Research}

The results from this research will be interesting to both researchers and practitioners. Researchers would benefit from understanding the potential mediating effects perceived trust has on perceived usefulness and perceived response time has on perceived ease of use. These findings would provide practitioners a greater understanding of how perceived trust and response time could enhance or reduce image-blog adoption. 


\section{References}

1. Blood, R.: Weblogs: A History and Perspective. Rebecca's PocketRebecca's Pocket (2000)

2. Caber, M., et al.: The Classification of Extranet Attributes in Terms of Their Asymmetric Influences on Overall User Satisfaction: An Introduction to Asymmetric ImpactPerformance Analysis. Journal of Travel Research 52(1), 106-116 (2013)

3. Davis, F., et al.: User Acceptance of Computer Technology: A Comparison of Two Theoretical Models. Management Science 35(8), 982-1003 (1989)

4. Loiacono, E., et al.: The Effect of Web Site Quality on Intention to Revisit and Purchase. International Journal of Electronic Commerce 11(3), 51-87 (2007)

5. McGrail, M.: The Blogconomy: Blogging Stats (2013)

6. (November 1, 2013), http: / /Merriam-Webster.com

7. Venkatesh, V.: Determinants of Perceived Ease of Use: Integrating Perceived Behavioral Control, Computer Anxiety and Enjoy into the Technology Acceptance Model. Information System Research 11(4), 342-365 (2000)

\section{Appendix 1: WebQual Items}

Usefulness
1. Information Fit-to-Task
2. Tailored Communications
3. Online Completeness
4. Relative Advantage
Ease of Use
5. Ease of Understanding
6. Intuitive Operation
7. Trust
8. Response Time
Entertainment
9. Visual Appeal
10. Innovativeness
11. Emotional Appeal
12. Consistent Image




\section{Appendix 2: Survey Items}

\section{Trust:}

- This social networking site is trustworthy.

- This social networking site vendor gives the impression that it keeps promises and commitments.

- I believe that this social networking site vendor has my best interests in mind.

\section{Response Time:}

- When I use the image-blog there is very little waiting time between my actions and the image-blog's response.

- The image-blog loads quickly.

- The image-blog takes long to load.

\section{Intention to Use:}

- I am likely to disclose personal information on this social networking site.

- I am likely to recommend this social networking site to my friends.

- I am likely to disclose personal information on this social networking site in the future.

\section{Perceived Usefulness:}

- Using the T/P/V enabled me to carry out product information search more quickly.

- Using the T/P/V improved my performance in product information search.

- Using the T/P/V increased my productivity in product information search.

- Using the T/P/V enhanced my effectiveness in product information search.

- Using the T/P/V made it easier to search for product information.

- I found the T/P/V useful in product information search.

\section{Perceived Ease of Use:}

- It was easy for me to make use of the T/P/V.

- I found it easy to get the T/P/V to do what I want it to do.

- My interaction with the T/P/V was clear and understandable.

- I found the T/P/V flexible to interact with.

- I was easy for me to become skilful at using the T/P/V.

- I found the T/P/V easy to use. 